\title{
Somatic Embryogenesis in Three Magnolia Species
}

\author{
S.A. Merkle and A.T. Wiecko \\ School of Forest Resources University of Georgia, Athens, GA 30602 \\ Additional index words. Magnolia virginiana, Magnolia acuminata var. cordata, Magnolia fraseri, sweetbay magnolia, \\ yellow cucumbertree, fraser magnolia, tissue culture
}

\begin{abstract}
Cultures were initiated from immature seeds of three species of magnolia: sweetbay magnolia (Magnolia virginiana L.), fraser magnolia (M. fraseri Walt.) and yellow cucumbertree [M. acuminata var. cordata (Michx.) Sarg.]. Immature seeds were bisected longitudinally and cultured on a solidified conditioning medium containing 2 $\mathrm{mg}$ 2,4-D/liter, $0.25 \mathrm{mg} \mathrm{BA} / \mathrm{liter}, 40 \mathrm{~g}$ sucrose/liter, and $1 \mathrm{~g}$ casein hydrolysate/liter. Cultures were maintained in the dark at $22 \mathrm{C}$ and transferred to fresh medium at monthly intervals. Within 2 months of culture, somatic embryos or proembryogenic masses proliferated from one end of the endosperm mass. Somatic embryos and proembryogenic masses of each species were cultured on a hormone-free version of the conditioning medium to complete maturation and then transferred to the same hormone-free medium, minus casein hydrolysate, to initiate germination. Germinants were transferred to a hormone-free plantlet development medium for conversion. Plantlets of all three species survived transfer to soil mix and continued to grow. Chemical names used: (2,4 -dichlorophenoxy) acetic acid (2,4-D), $N$ (phenylmethyl)-1H-purin-6-amine (BA).
\end{abstract}

The genus Magnolia numbers some 80 species scattered throughout southern and eastern Asia, Mexico to Venezuela, and the eastern United States. Of the nine species native to the United States, many are highly desirable as ornamental because of their beautiful foliage and large, showy flowers and fruits. Gardiner (1989) offers detailed descriptions and photographs of several magnolia species in a recent book. Magnolia virginiana L., sweetbay magnolia, is found over a large geographic range in the coastal plain and piedmont of the eastern United States where it occupies low areas and deep, rich soils. It varies widely in habit from a large multi-stemmed deciduous shrub in northern locations to a medium-sized evergreen tree on good sites in the South. The species bears fragrant, white flowers and crimson fruit. Magnolia fraseri Walt., fraser magnolia, is a small to medium tree native to the rich woods of the southern Appalachians. It has large leaves, up to $30 \mathrm{~cm}$ long, characterized by auriculate lobes at the base and fragrant, milky white to pale yellow flowers. Magnolia acuminata var. cordata (Michx.) Sarg., yellow cucumbertree, ranges in habit from a large, spreading shrub to a medium-sized tree. It is a rare species, restricted mainly to several counties in Georgia, but has also been reported in Alabama, Florida, and the Carolinas. Trees produce canaryyellow or, rarely, orange-colored, tulip-shaped blossoms.

Magnolias can be propagated from seeds, by rooted cuttings, chip budding, grafting, or layering (Hartmann and Kester, 1983; Gardiner, 1989). To date, there have been no reports of the tissue culture propagation of magnolias, although $M$. grandiflora and $M$. soulangiana embryos have been germinated in vitro (Le Page-Degivry, 1970). Another member of the Magnoliaceae, yellow-poplar (Liriodendron tulipifera L.), has been regenerated via somatic embryogenesis (Merkle and Sommer, 1986). Here we report somatic embryogenesis in sweetbay magnolia, fraser magnolia, and yellow cucumbertree, and detail regeneration of plantlets from the somatic embryos.

\footnotetext{
Received for publication 5 Feb. 1990. We thank Claud Brown, Bill Lott, and Sharon and Roy Maddox for help in obtaining plant materials. and Hazel Wetzstein, Harry Sommer, and Dayton Wilde for advice in preparing the manuscript. This work was supported by McIntire-Stennis funds allocated to the Univ. of Georgia School of Forest Resources. The cost of publishing this paper was defrayed in part by the payment of page charges. Under postal regulations, this paper therefore must be hereby markedadvertisement solely to indicate this fact.
}

\section{Materials and Methods}

Because sweetbay magnolia trees were readily accessible while fraser magnolia and yellow cucumbertree were not, plant material for explanting into culture was handled differently for each species.

Sweetbay magnolia. Developing fruits (aggregates of follicles) were sampled from 10 ornamental sweetbay magnolia trees growing on the Univ. of Georgia campus at weekly intervals from 2 to 7 weeks postanthesis (2 June -14 July 1989). Fruits only contained a few filled seeds; therefore, collections from trees were bulked for each sampling date. For the first three sampling dates, whole aggregate fruits were disinfested using the following sequence: $70 \%$ ethanol for 20 see, $10 \%$ Roccal (National Laboratories, Montvale, N. J.) for 1 min (repeating the ethanol and Roccal steps once), full-strength Clorox (5.25\% sodium hypochlorite) for 5 rein, sterile water rinse for 3 rein, $0.01 \mathrm{M} \mathrm{HCl}$ rinse for $3 \mathrm{rein}$, and three additional sterile water rinses. Aggregates were dissected aseptically to remove seeds. For the last four sampling dates, when aggregates were 5 to 7 $\mathrm{cm}$ long, seeds were excised from the fruits, then disinfested using the same sequence as was used for the fruits. At least 30 seeds from the bulked 10-tree sample were explanted for each sample date.

Fraser magnolia. Developing fruits were sampled only once from three fraser magnolias growing naturally near Brasstown Bald in Towns County, Ga. All three trees were within $20 \mathrm{~m}$ of each other and were sampled on 7 July, $\approx 5$ weeks postanthesis. Fruits were 8 to $10 \mathrm{~cm}$ long and mostly green, but beginning to show some pink. Seeds were removed for disinfestation as with sweetbay magnolia seeds. Thirty seeds were cultured from each of the three trees.

Yellow cucumbertree. Developing fruits were sampled twice from a single yellow cucumbertree in Oglethorpe County, Ga. Samples were collected $\approx 3$ (7 June) and 9 weeks post-anthesis (17 July). A very low percentage of the seeds were filled because this tree is insect-pollinated and was the only one in the vicinity. For the first sample, whole fruits were disinfested and seeds excised aseptically using the same method as for sweetbay magnolia fruit. For the second sample, seeds were excised and disinfested. Thirty-seven seeds were cultured from the first sampling date, but only nine seeds were cultured from the second one.

Culture media and treatment of explants. For all three species, seeds were bisected longitudinally with a scalpel and the 
halves were placed cut surface downward in 60-mm plastic petri dishes (three seeds per dish) on yellow-poplar conditioning medium (Merkle and Sommer, 1986) containing 2,4-D at 2 $\mathrm{mg} \cdot$ liter $^{-1}$, BA at $0.25 \mathrm{mg} \cdot \mathrm{liter}^{-1}$ casein hydrolysate $(\mathrm{CH})$ at $1 \mathrm{~g} \cdot \operatorname{liter}^{-1}$, and sucrose at $40 \mathrm{~g} \cdot \operatorname{liter}^{-1}$. Cultures were maintained at $22 \mathrm{C}$ in darkness and transferred to fresh medium monthly. Following the appearance of proembryogenic masses (PEMs) or embryos, some were transferred for further development to yellow-poplar basal medium that lacked hormones, still in darkness. Mature embryos were transferred to a medium of the same formulation, but lacking $\mathrm{CH}$, to promote germination and grown under fluorescent light. We had previously found that removal of $\mathrm{CH}$ from the basal medium promoted germination of mature yellow-poplar somatic embryos, probably by reducing the water potential of the medium (unpublished data). Germinants were moved to test tubes containing $20 \mathrm{ml}$ of yellow-poplar plantlet development medium (Merkle and Sommer, 1986) containing no hormones and $2 \%$ sucrose, also under fluorescent light. To initiate suspension cultures, some PEM-like embryos were inoculated into liquid conditioning medium and grown in darkness at $22 \mathrm{C}$ and with shaking at $90 \mathrm{rpm}$. Also, we attempted to induce cultures to proliferate in a less-differentiated state (i.e., PEMs instead of globular embryos) by initiating subcultures of each embryogenic line on solidified conditioning medium with the 2,4-D level increased to $4 \mathrm{mg} \cdot$ liter $^{-1}$.

\section{Results and Discussion}

Sweetbay magnolia. Most sweetbay magnolia explants produced large amounts of nonmorphogenic callus within 4 weeks after being placed in culture. In addition, some cultures produced somatic embryos that originated directly from one end of the explanted seed halves and that we presumed to be the locations of the zygotic embryos. However, we cannot be certain that the zygotic embryos were the source of the somatic embryos, because at the time of explanting, we could not locate embryos in the seeds. Globular-stage somatic embryos were first observed proliferating from 3 -weeks post-anthesis seeds 5 weeks after explanting. Additional embryogenic cultures arose over the next few weeks, mainly from seeds explanted on the same date (12 embryogenic cultures out of 45 seeds), but also from seeds explanted 2 weeks postanthesis (two embryogenic cultures out of 48 seeds) and 5 weeks post-anthesis (one embryogenic culture out of 36 seeds). Embryogenesis took two forms that appeared to depend on explanting date. Embryos from the two earliest cultures ( 2 weeks post-anthesis) appeared most similar to PEMs seen in. many indirect embryogenic systems, such as carrot [Daucus carota L. (Halperin, 1966)], and proliferated at the highest rate. Somatic embryos from later cultures appeared to be produced by direct embryogenesis, with no intermediate callus or PEMs (Fig. 1A). PEM-like embryos inoculated into liquid medium proliferated rapidly but did not form cell suspensions. Instead, they grew as clusters of globular embryos that would break apart and initiate new clusters. Subcultures to the higher auxin level $\left(2,4-\mathrm{D}\right.$ at $4 \mathrm{mg} \cdot \mathrm{liter}^{-1}$, appeared to promote production of PEMs along with more rapid proliferation of the cultures.

Somatic embryos maintained on solid conditioning medium, although mostly malformed, often continued development through the torpedo stage and continued to swell but would not germinate. Instead, cotyledons remained fused and secondary embryos formed at the radicle ends. PEMs and globular stage embryos transferred to basal medium appeared to complete development normally, resulting in torpedo-stage embryos with
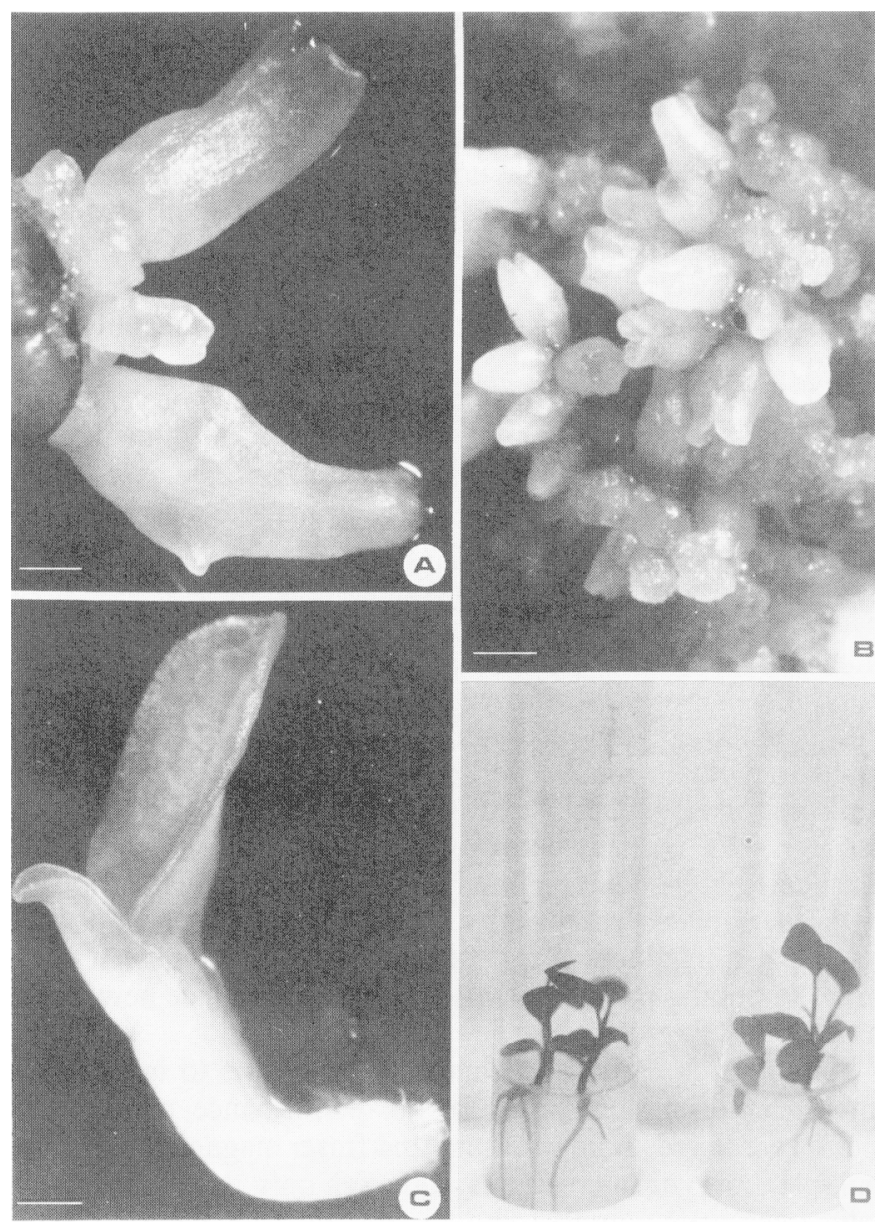

Fig. 1. Somatic embryogenesis in sweetbay magnolia. (A) Somatic embryos arising by direct embryogenesis from end of an immature sweetbay magnolia seed. (B) Torpedo- and cotyledon-stage somatic embryos arising from mass of sweetbay magnolia proembryogenic masses. (C) Germinating somatic embryo. (D) Somatic embryoderived sweetbay magnolia plantlets. Bar in all photos $=500 \mu \mathrm{m}$.

two to three separated cotyledons (Fig. 1B). However, germination of these mature embryos remained inhibited until they were transferred to basal medium without $\mathrm{CH}$ and placed in light, whereupon cotyledons became green and expanded and radicles elongated (Fig. 1C). Embryos continued germination (i.e., root elongation) following transfer to plantlet development medium, but apical development was very slow and ceased in $\approx 75 \%$ of the germinants. About $25 \%$ of the embryos completed conversion to form seedling-like plantlets (Fig. 1D). Plantlets transferred to Peat-Lite (Fafard, Springfield, Mass.) potting mix, placed in a humidifying chamber, and fertilized with a modified Hoagland's solution weekly continued to produce new leaves at a rate of one every 2 to 3 weeks.

Fraser magnolia. Fraser magnolia explants responded very quickly to culture on conditioning medium, with PEMs first appearing only 3 weeks after explanting. Within 5 weeks, 11 of 90 seeds, representing all three sample trees, had produced PEMs. PEMs proliferated slowly and, unlike sweetbay, magnolia embryogenic cultures, tended not to differentiate to globular stage embryos while on conditioning medium. PEMs inoculated into liquid conditioning medium proliferated more slowly than did those of sweetbay magnolia. Following transfer to solid basal medium, globular embryos differentiated within 
3 weeks and continued development (Fig. 2A). Cotyledons of torpedo-stage embryos transferred to basal medium lacking $\mathrm{CH}$ and placed in the light expanded and greened, but, unlike sweetbay "magnolia somatic embryos, $\approx 90 \%$ failed to germinate on this medium. Upon transfer to plantlet development medium, radicles of some embryos elongated and cotyledon expansion continued. The first true leaves were produced after 3 to 4 weeks. Plantlet transferred to potting mix, placed in the humidifying chamber and fertilized as described for sweetbay magnolia continued w.

Yellow Cucumbertree. Only one explanted seed of yellow cuumbers produced somatic embryos, 6 weeks following culture initiation. Embryogenic material first appeared as a rapidly proliferating mixture of PEMs and globular-stage somatic embryos on conditioning medium (Fig. 2B). As with the other species, PEMs could also be maintained in liquid conditioning medium. However, transfer of PEMs to basal medium failed to induce the PEMs or globular embryos to develop further. Finally, PEMs were transferred to filter paper disks that were placed on top of basal medium, a procedure we have previously applied to obtain mature yellow-poplar somatic embryos (unpublished data). After 5 to 6 weeks, somatic embryos differentiated. As with sweetbay. magnolia, embryos could be germinated in the light on basal medium without $\mathrm{CH}$ and $\approx 10 \%$ of the germinants continued to grow upon transfer to plantlet development medium. A few of these plantlets have been transferred to potting mix and have continued to produce new leaves in a humidiyfing chamber.

The genus Magnolia appears to be amenable to initiation of embryogenic cultures based on the performance of the three species we tested. Both sweetbay and fraser magnolias produced multiple embryogenic cultures, although only three fraser magnolia trees were sampled and developing fruit were collected only on a single date. The inability to obtain more than one embryogenic culture from yellow cucumbertree was probably an effect of very low percentage of filled seed. Although the seeds cultured from this species appeared to be full-sized, indicating they were filled, we found no zygotic embryos. Thus,

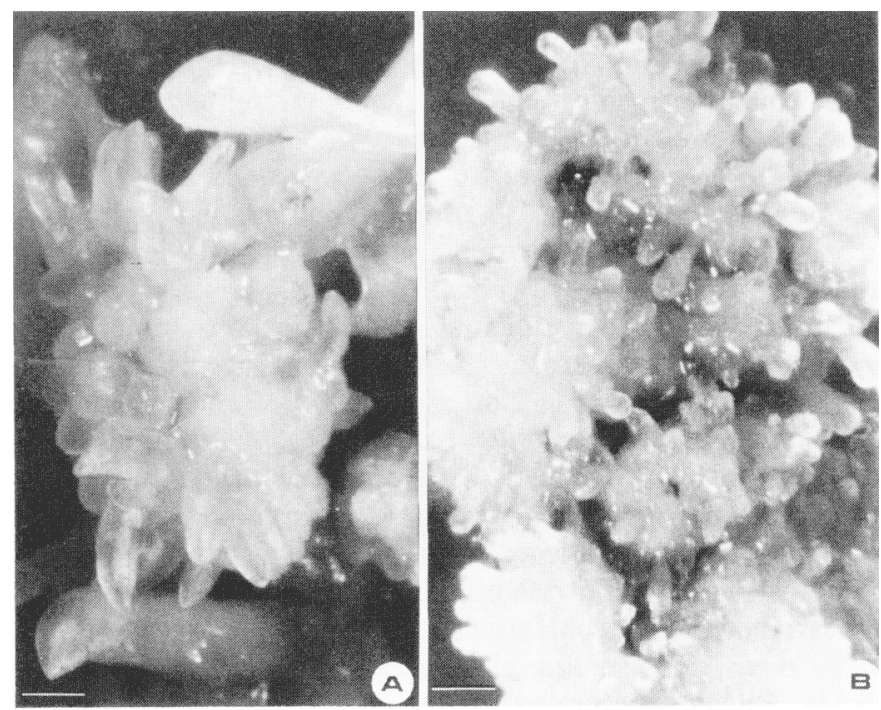

Fig. 2. Somatic embryogenesis in fraser magnolia and yellow cucumbertree. (A) Fraser magnolia somatic embryos. (B) Mass of yellow cucumbertree proembryogenic masses and globular stage somatic embryos. Bar in both photos $=500 \mu \mathrm{m}$. many of the seeds placed in culture may not have contained viable embryos.

Our results with sweetbay magnolia indicate that an early stage of development may be optimum for explanting the zygotic embryo (and other seed components) to initiate an embryogenic culture. The group of seeds producing the highest percentage of embryogenic cultures was explanted only 3 weeks post-anthesis, when embryos were too small to be found under a dissecting microscope. The globular stage of embryo development was found to be optimum for initiation of embryogenic cultures of the related yellow-poplar species (Merkle et al., 1989).

Although the protocol for initiation of embryogenic magnolia cultures was very similar to that for yellow-poplar (e.g., use of immature zygotic embryos, same media), growth characteristics of the cultures differed. Yellow-poplar cultures invariably formed PEMs on media with $2 \mathrm{mg}$ 2,4-D/liter and produced somatic embryos via indirect embryogenesis when transferred to hormone-free induction medium. PEMs would readily form cell suspensions in liquid 2,4-D-supplemented media. In contrast, the magnolia cultures did not readily form PEMs, even when the 2,4-D level was raised to $4 \mathrm{mg} \cdot \mathrm{liter}^{-1}$. Cultures were mixtures of PEMs and somatic embryos at globular or later stages of development that appeared to proliferate via direct embryogenesis. Magnolia PEMs and embryos transferred to liquid conditioning medium did not form true cell suspensions, but continued to produce new PEMs or embryos in large clusters. These in turn broke apart to initiate new clusters. Finally, in comparison to yellow-poplar embryos given the same conversion treatment, magnolia embryos formed plantlets very slowly or failed to complete conversion. Although root elongation in sweetbay magnolia and yellow cucumbertree proceeded at rates similar to that in yellow-poplar, the magnolia plantlets produced leaves much more slowly than did the yellow-poplar. Height growth rate was similarly reduced. However, it is possible that the relative rates of leaf production and height growth may also hold for seedlings of these species and not be specific to somatic embryo-derived plantlets.

Our results indicate that embryogenic cultures may provide a means of mass propagation of magnolia species. The cultures, which we believe to be derived from immature zygotic embryos in the explanted seeds, have continued to produce somatic embryos and plantlets for $>8$ months. The potential of this tissue culture system may be especially useful for propagation of some of the rare native species of magnolia, such as yellow cucumbertree.

\section{Literature Cited}

Gardiner, J.M. 1989. Magnolias: Their care and cultivation. Cassell, London.

Halperin, W. 1966. Alternative morphogenetic events in cell suspensions. Amer. J. Bet. 53:443453.

Hartmann, H.T. and D.E. Kester. 1983. Plant propagation principles and practice. 4th ed. Prentice Hall, Englewood Cliffs, N.J.

Le Page-Degivry, M.T. 1970. Seed dormancy associated with embryo immaturity: Contribution for the study of Magnolia soulangeana SouL Bed. and Magnolia grandiflora L. by means of in vitro culture. Planta 90:267-271.

Merkle, S.A. and H.E. Sommer. 1986. Somatic embryogenesis in tissue cultures of Liriodendron tulipfera. Can. J. For. Res. 16:420422 .

Merkle, S. A., R.J. Sotak, A.T. Wiecko, and H.E. Sommer. 1989. Optimization of the yellow-poplar embryogenic system. Proc. 20th Southern For. Tree Imp. Conf. Charleston, S.C. p. 186-193. 